\title{
The Mediating Effect of Depression in the Relationship between Sleep Misperception and Insomnia Severity among Insomnia Patients
}

\author{
Jiyun Lee ${ }^{1}$, Eun Yeon $\mathrm{Joo}^{2}$, Su Jung Choi ${ }^{2,3}$, Sooyeon $\mathrm{Suh}^{1}$ \\ ${ }^{1}$ Department of Psychology, Sungshin Women's University, Seoul, \\ ${ }^{2}$ Department of Neurology, Neuroscience Center, Samsung Medical Center, Sungkyunkwan University School of Medicine, Seoul, \\ ${ }^{3}$ Department of Nursing, Department of Clinical Nursing Science, Samsung Medical Center, Sungkyunkwan University School of Medicine, \\ Seoul, Korea
}

수면 오지각이 불면증 심각도에 미치는 영향: 우울의 매개 효과

이지윤 ${ }^{1}$, 주은연 ${ }^{2}$, 최수정 ${ }^{2,3}$, 서수연 ${ }^{1}$

성신여자대학교 심리학과, ${ }^{1}$ 성균관대학교 의과대학 삼성서울병원 신경과, 뇌신경센터, ${ }^{2}$ 삼성서울병원 간호부, 성균관대학교 임상간호대학원 ${ }^{3}$

Received November 8, 2020

Revised December 7, 2020

Accepted December 15, 2020

Address for correspondence Sooyeon Suh, PhD

Department of Psychology, Sungshin Women's University,

2 Bomun-ro 34da-gil,

Seongbuk-gu, Seoul 02844, Korea

Tel: $+82-2-920-7215$

Fax: +82-2-920-2040

E-mail: alysuh@sungshin.ac.kr
Objectives: Sleep misperception is the underestimation of perceived total sleep time compared to actual total sleep time. It is observed in approximately $50 \%$ of patients with insomnia. Insomnia patients with sleep misperception report significantly higher depression than those without sleep misperception. Depression is one of the most consistent risk factors for predicting insomnia. Therefore, this study attempted to confirm the mediating effect of depression in exacerbating insomnia. Methods: This study included 77 male and female aged 18-40 years who met diagnostic criteria for insomnia disorder based on the Diagnostic and Statistical Manual of Mental Disorders, Fifth Edition. Depression and insomnia severity were measured using self-report questionnaires, and actigraphy data were collected for 1 week. The sleep misperception index was calculated using the sleep diary and actigraphy. Results: The Pearson correlation analysis was performed to examine the relationships between sleep misperception, insomnia, and depression. Sleep misperception was positively associated with depression $(r=0.399, p<0.01)$. There was also a significant positive correlation between depression and insomnia severity $(\mathrm{r}=0.591, p<0.01)$. However, there was no significant correlation between sleep misperception and insomnia severity $(\mathrm{r}=0.210, p=0.07)$. Depression was found to have a full mediating effect on the relationship between sleep disturbance and severity of insomnia ( $\mathrm{n}=77, \mathrm{~B}=6.1688,95 \%$ confidence interval $=2.9960,10.4562)$. Conclusions: This study verified the mediating effect of depression on the relationship between sleep misperception and insomnia severity. The results highlight the importance of considering depression and sleep misperception in insomnia treatment.

J Sleep Med 2020;17(2):159-166

Key Words: Sleep misperception, Depression, Insomnia, Actigraphy.
서 론

수면 오지각(sleep misperception)이란 주관적으로 인지한 수면과 객관적으로 측정한 수면 지표 간의 불일치를 의미한 다. ${ }^{1}$ 선행연구에 따르면 불면증 환자의 수면 오지각 발병률은

This is an Open Access article distributed under the terms of the Creative Commons Attribution Non-Commercial License (https://creativecommons.org/licenses/by-nc/4.0) which permits unrestricted non-commercial use, distribution, and reproduction in any medium, provided the original work is properly cited.
약 9.2 50\%에 달한다. ${ }^{2}$ 수면다원검사나 액티그래피를 통해 측정된 객관적인 수면 지표를 확인하였을 때, 불면증 환자들 은 총 수면시간(total sleep time)을 과소평가하며, 수면 잠복 기(sleep onset latency)와 입면 후 각성 시간(wake after sleep onset)에 대해 과대평가하는 수면 오지각 경향이 확인되었 다. $^{3}$ 수면 오지각은 주로 불면증을 않고 있는 사람들에게서만 관찰되어 주관적인 수면 지표와 객관적인 수면 지표 사이의 불일치는 불면증의 주요한 특징으로 인식되기 시작했다. ${ }^{4-6}$ 
수면 오지각을 보이는 불면증 환자가 수면 오지각이 없는 환자보다 불면증이 심각하다. ${ }^{7}$ 실제로 수면 오지각을 보이는 환자는 스스로 수면을 충분히 취하지 못하고 있다고 생각하 여 수면 문제에 대한 걱정이 점진적으로 증가하는 것으로 보 고되었다. ${ }^{8}$ 수면 오지각은 수면에 대한 과도한 주의와 걱정을 유발하는 것 뿐만 아니라 불안과 과다각성을 증가시켜 불면 증을 지속되게 한다. ${ }^{9}$ 수면 오지각을 보이는 환자들은 객관 적으로 양호한 수면을 보이다가 점차적으로 실제 수면 부족 의 문제로 발전할 가능성이 매우 높다. ${ }^{9}$ 따라서 임상장면에서 불면증을 진단할 때, 수면 오지각을 염두하고 문진해야 할 필요가 있다. ${ }^{9}$

수면 오지각이 있는 불면증 환자는 수면 오지각이 없는 불 면증 환자와는 유의미하게 구별되는 심리적 특징이 있는 것 으로 보인다. 수면 오지각으로 인해 총 수면시간이 정상범 위에 있음에도 불구하고 수면의 부족을 호소하는 불면증 환 자들은 그렇지 않은 사람들에 비해 유의미하게 높은 우울과 불안, 낮은 자아강도를 보고했다. ${ }^{10}$ 더불어 Vgontzas 등의 연 구에서는 불면증 환자의 수면 오지각이 우울, 대처 자원의 부 족과 같은 심리적 요인과 연관이 있을 가능성을 시사했다.

선행연구에 따르면 수면 오지각이 클수록 우울의 심각도 가 높은 것으로 나타났다. ${ }^{11}$ 이는 불면증 환자들이 수면 오지 각으로 인해 스스로 적절한 수면을 취하지 못했다는 생각으 로 인해, 심리적 고통이 증가한 결과일 수 있다. ${ }^{9}$ 수면 오지각 을 동반한 불면증 환자들이 수면 오지각이 없는 불면증 환자 들에 비해 훨씬 더 심각한 우울을 경험하며, 수면 오지각이 심각해짐에 따라 우울 또한 심화되는 결과는 이와 같은 가 설을 지지한다. ${ }^{10,12-14}$

우울은 불면증을 유지하고 심화하는 강력한 예측요인이자 지속요인으로, 우울증 환자들이 가장 일반적으로 경험하는 공병 장애는 바로 불면증이다. ${ }^{15}$ 우울증 환자들의 $75 \%$ 는 수 면의 어려움을 호소하며 수면 개시의 어려움과 조기 기상이 가장 두드러지는 불면 증상이다. ${ }^{16}$ 우울증과 불면증에 관한 종단연구들에 대한 메타 분석이 실시되었는데, 해당 논문에 서는 우울증과 불면증 간에 인과적인 영향이 있음을 시사하 고 있다. ${ }^{16}$ 우울증은 불면증의 가장 영향력 있고 일관적인 위 험요인이며 불면증을 촉발할 뿐만 아니라 동시에 심화하는 요인으로 제시되었다. ${ }^{16-18}$ 그러나 다양한 선행 연구가 제시 되었음에도 불구하고 수면 오지각과 불면증의 관계에서 우 울의 역할에 대해 알아본 연구는 드물었다.

따라서 본 연구는 불면증 환자들을 대상으로 수면 오지각 과 우울, 불면증 심각도의 연관성을 분석하고, 수면 오지각과 불면증 심각도 간의 관계에 있어 우울의 매개효과를 검증해 보고자 한다(Fig. 1). 이를 통해, 불면증을 유지하고 심화하는

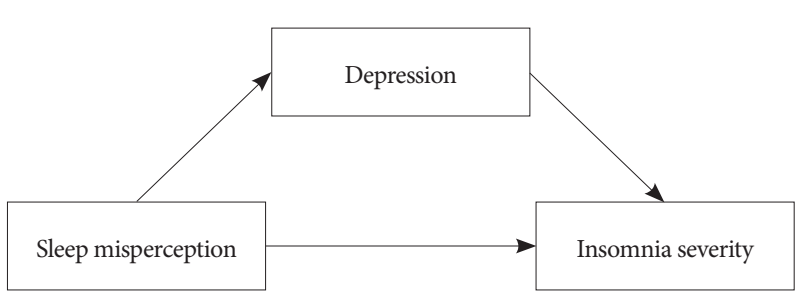

Figure 1. The mediation model of depression between the relation of sleep misperception and insomnia severity.

기제와 수면 오지각이 불면증을 심화하는 양상에 대한 이해 가 증진될 것을 기대한다. 더불어, 향후 수면 오지각이 있는 불면증 환자에게 우울을 다루는 개입을 통해 불면증의 치료 효과가 향상될 것을 기대한다.

\section{방 법}

\section{연구 대상}

본 연구는 한국연구재단의 신진연구사업의 일환으로 2017 년 3월 1일 2019년 2월 28일까지 진행된 연구이다. 본 연구 는 불면증을 호소하는 만 18 세에서 40 세 사이의 피험자를 대 상으로 실시하였다. 온라인과 오프라인 홍보를 통해 자발적 으로 본 연구에 참여 신청을 한 일반인들에게 유선 상으로 스크리닝을 실시하였다. 본 연구는 불면증을 호소하는 집단 을 표집하기 위해 Diagnostic and Statistical Manual of Mental Disorders-fifth edition(DSM-5)에 명시된 불면증 기준을 만족하며 수면에 영향을 줄 수 있는 요인을 통제하기 위해, 4주 이내 수면제 복용, 4주 이내 출국 등으로 인한 시차경험, 불면증에 대한 심리 치료 경험, 야간 교대근무, 양극성 장애 진단 과거력, 정신질환 증상이 있는 사람은 연구 대상에서 제외했다. ${ }^{19}$ 그 결과, 99 명의 불면증 환자의 자료가 수집되었 고, 본 연구에서는 이 중, 분석 가능한 액티그래피 데이터가 산출된 77명의 자료만 사용하였다. 본 연구는 기관생명윤리 위원회의 심의를 거쳐 시행되었다(SSWUIRB 2017-030).

\section{측정 도구}

수면

수면일지(Sleep diary)

본 연구는 개인의 주관적인 수면 지표를 측정하기 위해 총 7일 동안의 수면일지를 실시하였다. 연구 참여자들은 매일 아침, 그 전날의 수면에 대해 회고적으로 기록하게 되며, 이 를 통해 주관적인 수면 지표를 산출할 수 있다. 수면 일지를 통해 수집한 주관적인 수면 지표 중, 총 수면시간을 활용하 
여 수면 오지각 지수를 산출하는 데 사용하였다.

액티그래피(Actigraphy)

본 연구는 개인의 객관적인 수면 지표를 측정하기 위해 개 인의 물리적인 활동량의 정보를 기반으로 수면-각성 주기 를 산출하는 액티그래피를 활용하였다. 본 연구에서는 액티 그래피 기기인 액티와치(Actiwatch 2, Philips Respironics, $\mathrm{Bend}, \mathrm{OR}, \mathrm{USA}$ )를 활용하였으며 참여자들은 총 7일 동안 액티와치를 착용하였다. 측정된 데이터는 Actiware 6(Philips Respironics) 소프트웨어를 통해 분석하여 수면-각성 주 기와 객관적인 수면 지표를 산출하였다. 액티그래피의 1 판 독단위(epoch length)는 30초로 설정하였으며, 각성 역치 (activity threshold)는 40으로 설정하였다. 10분간 각성이 없 는 기간이 처음 나타났을 때부터 수면의 시작으로 판단하였 다. ${ }^{20,21}$ 연구 참여자에게서 회수한 액티그래피에서 산출한 자 료는 액티그래피 미착용, 오측정, 기계 오류 등의 이유로 별 도의 데이터 클리닝 단계가 필요하다. 액티그래피 데이터 클 리닝은 선행 연구를 참고하여 아래와 같이 실시하였다. ${ }^{22}$

본 연구에서는 선행연구에서 제안한 신뢰할 수 있는 성인 의 일상생활의 활동량을 추정하기 위해 필요한 최소 측정기 간(3 5일)을 수용하여 최소 4일동안 안정적으로 표집된 데 이터만을 대상으로 데이터 클리닝을 실시하였다. $22-24$ 모든 클리닝 과정을 마친 뒤, 4일 이상의 타당한 수면-각성 주기 데이터가 확보된 데이터만을 최종 분석에 포함하였다.

수면 오지각 지표(Sleep Misperception Index, MI)

수면 오지각을 정량화하여 산출하는 방법은 선행 연구마 다 매우 이질적이다. 수면 오지각을 측정하기 위해 채택된 일반적인 방법은, 백분율로 주관적인 총 수면시간과 객관적 인 총 수면 시간의 비율을 산출하는 것이다. ${ }^{4,25}$ 그러나 주관 적인 수면의 비율은 상대적인 수면 오지각의 수준을 알려줄 수 있으나, 객관적인 총 수면시간과 주관적인 총 수면시간 간의 절대적인 오차의 크기를 나타내지 못한다는 한계가 있 다. 이와 같은 한계를 보완하기 위해 본 연구는 Manconi 등 (2010)에서 제시한 새로운 수면 오지각 지수(MI)를 활용하였 다. ${ }^{5}$ 해당 지표의 계산방식은 Table 1 에 제시하였다. 수면 오 지각이 없는 경우, 즉 주관적인 총 수면시간과 객관적인 총 수면시간이 같을 경우에 수면 오지각 지수는 0으로 계산되

Table 1. Misperception Index (MI) formula

\begin{tabular}{cc}
\hline Term & Formula \\
\hline MI & Objective TST-Subjective TST \\
\cline { 2 - 2 } & Objective TST \\
\hline
\end{tabular}

TST: total sleep time
며, 총 수면시간을 과소평가하는 경우 양의 값으로, 총 수면 시간을 과대평가하는 경우 음의 값으로 나타난다.

불면증 심각성 척도(Insomnia Severity Index)

본 연구에서는 연구 참여자의 불면증 심각도를 알아보기 위해 Bastien 등이 개발하고 Cho 등이 타당화한 불면증 심각 성 척도(Insomnia Severity Index)를 활용하였다. 26,27 총 7개 의 문항으로 각 문항은 5점 Likert 척도이며 총점의 범위는 0 28점이다. 한국판 타당화 연구에 따르면 총점 15점 이상 일 때, 임상적인 수준의 불면증으로 볼 수 있다.

\section{우울}

역학연구 우울척도 개정판(Center for Epidemiologic

Studies-Depression Scale-Revised)

Eaton 등이 개정하고, Lee 등이 표준화한 한국판 Center for Epidemiologic Studies-Depression Scale-Revised를 사 용하였다. 28,29 지난 일주일 동안 경험한 우울 증상의 빈도를 평가하는 총 20 문항으로 구성되어 있으며, 각 문항은 5점 Likert 척도이고 총점의 범위는 0 80점으로 점수가 높을수 록 우울 수준이 심각함을 의미한다.

\section{자료 분석 방법}

본 연구의 자료 분석은 SPSS 21.0 version(IBM Corp., Armonk, NY, USA)으로 실시하였으며, 연구 참여자의 인구 통계학적 특성을 파악하고 측정 변수들의 평균 및 표준편차 를 산출하기 위해 빈도분석과 기술통계를 실시하였다.

불면증 집단의 수면 오지각과 우울, 불면증 심각도 간의 관계를 살펴보기 위해 각 변인들을 측정하는 질문지와 수면 일지, 액티그래피로 측정한 수면 지표들을 통해 산출한 수면 오지각 간의 Pearson 상관분석을 실시하였다. 마지막으로 불면증 집단의 수면 오지각에 따라 불면증 심각도에 미치는 영향을 우울이 매개하는지 알아보기 위해 SPSS PROCESS 를 활용하여 매개분석을 실시하였다.

\section{결 과}

\section{인구통계학적 특성}

본 연구에서는 불면증을 호소하는 만 18 세에서 40 세 사이 의 피험자 총 99 명의 자료가 수집되었으며, 액티그래피 데이 터 클리닝을 거쳐 미착용 및 오작동 등으로 데이터가 손실된 22 명을 제외한 총 77 명의 자료에 대해 분석을 실시하였다.

분석 결과, 연구 대상자 중 남성은 42 명 $(54.5 \%)$, 여성은 35 
Table 2. Subjective sleep measurements and objective sleep measurements $(n=77)$

\begin{tabular}{|c|c|c|c|c|}
\hline & \multicolumn{2}{|c|}{ Subjective sleep measurements* $(n=77)$} & \multicolumn{2}{|c|}{ Objective sleep measurements ${ }^{\dagger}(\mathrm{n}=77)$} \\
\hline & M & SD & M & SD \\
\hline Sleep onset latency (min) & 60.00 & 36.29 & 26.05 & 20.52 \\
\hline Wake after sleep onset (min) & 28.53 & 23.33 & 44.87 & 17.72 \\
\hline Early morning awakening $(\min )(\mathrm{n}=65)$ & 64.76 & 47.88 & & \\
\hline Total sleep time (min) & 355.52 & 60.59 & 375.80 & 56.43 \\
\hline Sleep efficiency (\%) & 76.46 & 9.97 & 80.79 & 5.63 \\
\hline
\end{tabular}

${ }^{*}$ measured by sleep diary, ${ }^{\dagger}$ measured by actigraphy

명(45.5\%)이었으며, 평균 연령은 32.09( \pm 7.17$)$ 세로 나타났 다. 연구 대상자의 평균 불면증 심각도는 $18.15( \pm 4.25)$ 점이 었으며 평균 불면증 유병기간은 27.08개월로 나타났다. 연구 대상자의 평균 우울 점수는 19.18( \pm 10.98$)$ 점으로 나타났다.

\section{주관적인 수면 지표와 객관적인 수면 지표}

연구 참여자들은 주관적으로 평균 7시간 47분 동안 침대에 누워있었다고 보고하였으며, 수면 잠복기의 경우 연구 참여 자들은 주관적으로 평균 $60.00( \pm 36.29)$ 분이 걸렸다고 보고 하였으나, 객관적으로 측정한 결과 잠들기까지 평균 26.05 ( \pm 20.52$)$ 분이 걸린 것으로 나타났다. 입면 후 각성의 경우, 평균 26.53( \pm 23.33$)$ 분 깨어 있었다고 보고하였으나 객관적 으로는 평균 $44.87( \pm 36.29)$ 분 동안 수면 도중 깨어 있었던 것으로 측정되었다. 수면 효율성 또한 주관적인 지표상으로 는 평균 76.46 $( \pm 9.97) \%$ 로 나타났으나 객관적인 수면 지표를 통해 산출하였을 때 평균 $80.79( \pm 5.63) \%$ 의 수면 효율을 보 였다(Table 2).

\section{수면 오지각과 임상 지표와의 관계}

본 연구에서는 수면 오지각이 우울, 불면증 심각도와 같은 임상적 지표와 관련이 있는지 확인하였다. 수면 오지각의 경 우, 수면일지와 액티그래피로 측정한 수면 지표들을 통해 공 식에 따라 산출하였다. 수면 오지각, 우울과 불면증 심각도의 관계를 상관 분석을 통해 확인하였으며, 상관 분석에 대한 결과는 Table 3에 정리하여 제시하였다. 수면 오지각은 우울 과 유의한 정적 상관을 보였으며 $(\mathrm{r}=0.399, p<0.01)$ 우울과 불면증 심각도 또한 유의한 정적 상관을 나타냈다 $(\mathrm{r}=0.591$, $p<0.01)$. 수면 오지각과 불면증 심각도는 유의미한 상관을 보이지 않았다( $\mathrm{r}=0.210, p=0.07)$. 이는 수면 오지각이 높을수 록 더 우울할 수 있음을 의미하며, 우울이 심각할수록 불면 증이 더 심각해짐을 의미한다.

\section{수면 오지각과 불면증 심각도의 관계에서 우울의 매개효과}

수면 오지각과 불면증 심각도의 관계에서 우울의 매개효
Table 3. The correlation between sleep misperception, depression, and insomnia severity $(n=77)$

\begin{tabular}{lllc}
\hline & \multicolumn{1}{c}{1} & \multicolumn{1}{c}{2} & 3 \\
\hline 1. Sleep misperception $^{\dagger}$ & 1 & & \\
2. Depression $^{\ddagger}$ & $0.399^{* *}$ & 1 & \\
3. Insomnia Severity§ $^{\S}$ & 0.210 & $0.591^{* *}$ & 1 \\
M & 0.04 & 19.18 & 18.16 \\
SD & 0.17 & 10.98 & 4.25 \\
\hline
\end{tabular}

${ }^{* *} p<0.01,{ }^{\dagger}$ Misperception Index, ${ }^{\ddagger}$ Center for Epidemiologic Studies-Depression Scale-Revised, §Insomnia Severity Index

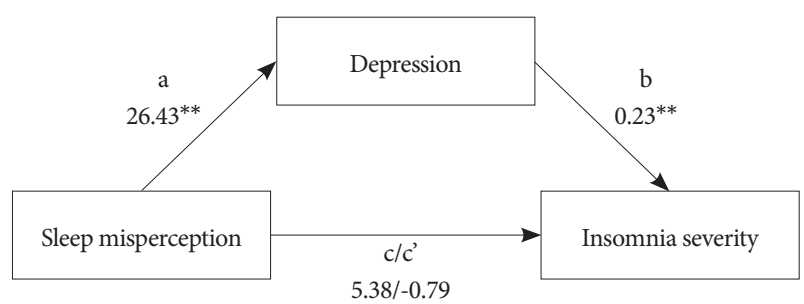

Figure 2. Statistical model for the mediating effect of depression between the relation of sleep misperception and insomnia severity. ${ }^{* *} p<0.01$.

과를 검증하기 위해 Baron과 Kenny가 제안한 단순 매개모 형을 활용하였으며 SPSS PROCESS를 통해 매개분석을 실 시하였다(Fig. 2).$^{30}$

수면 오지각을 독립변인으로, 우울을 종속변인으로 분석 실시한 회귀모형은 통계적으로 유의하였다 $[\mathrm{F}(1,75)=14.19$, $p<0.001)$. 수면 오지각은 우울에 정적으로 유의하였으며 수 면 오지각의 1 단위 증가할 때, 우울은 26.43 단위 증가하는 것으로 나타났다 $[\mathrm{B}=26.43, \mathrm{t}(75)=3.77, p<0.001)$. 불면증 심 각도를 독립변인으로, 수면 오지각과 우울을 종속변인으로 분석을 실시한 결과, 모형은 통계적으로 유의미한 것으로 나 타났다 $[\mathrm{F}(2,74)=19.90, p<0.001)$. 우울이 불면증 심각도를 통 계적으로 유의한 정적인 영향을 갖는 것으로 나타났다 $[\mathrm{B}=$ $0.23, \mathrm{t}(74)=5.90, p<0.001)$. 우울이 1 단위 높아질 때, 불면증 심각도는 0.23 단위 증가하는 것으로 나타났다. 그러나 수면 오지각은 불면증 심각도에 통계적으로 유의미한 수준의 효 과를 나타내지 못하였다[B=-0.79, $\mathrm{t}(74)=-0.30, p=0.764)$ 
Lee $\mathrm{J}$ et al.

Table 4. Mediating model of depression and insomnia severity

\begin{tabular}{|c|c|c|c|c|c|}
\hline \multirow{2}{*}{ Outcome variable } & \multirow{2}{*}{ Predictor variable } & \multirow{2}{*}{ B } & \multirow{2}{*}{ SE } & \multicolumn{2}{|c|}{ 95\% confidence interval } \\
\hline & & & & LLCI & ULCI \\
\hline Depression* & Sleep misperception ${ }^{\dagger}$ & 26.4264 & 7.0149 & 12.4518 & 40.4009 \\
\hline \multirow[t]{2}{*}{ Insomnia severity ${ }^{\ddagger}$} & Sleep misperception & -0.7907 & 2.6217 & -6.0146 & 4.4332 \\
\hline & Depression & 0.2334 & 0.0396 & 0.1546 & 0.3123 \\
\hline
\end{tabular}

*Center for Epidemiologic Studies-Depression Scale-Revised, ${ }^{\dagger}$ Misperception Index, ${ }^{\star}$ Insomnia Severity Index. SE: standard error, LLCI: lower limit confidence interval, ULCI: upper limit confidence interval

Table 5. Indirect effects of depression on the relationship between sleep misperception and insomnia severity

\begin{tabular}{lcccc}
\hline & \multirow{2}{*}{ Effect } & \multirow{2}{*}{ Boot SE } & \multicolumn{2}{c}{ 95\% confidence interval } \\
\cline { 3 - 5 } & & & LLCI & ULCI \\
\hline Depression* $^{*} 6.1688$ & 1.9161 & 2.9960 & 10.4562 \\
\hline
\end{tabular}

*Center for Epidemiologic Studies-Depression Scale-Revised. SE: standard error, LLCI: lower limit confidence interval, ULCI: upper limit confidence interval

(Table 4).

수면 오지각과 불면증 심각도의 관계에서 우울의 매개효 과를 검증하기 위해 SPSS PROCESS를 활용하여 Bootstrapping을 실시하였다. 결과는 Table 5에 제시하였다. 우울의 매개효과는 95\% 신뢰도에서 5,000회 Bootstrapping한 결과, $(2.9960,10.4562)$ 의 신뢰 구간이 나타나 통계적으로 유의미 한 수준으로 나타났다 $[\mathrm{B}=6.17,95 \%$ 신뢰구간(confidence interval) $(2.9960,10.4562)]$. 즉, 수면 오지각이 심각해질수록 우 울해지고, 이는 결국 주관적으로 불면증을 심각하고 고통스 럽게 하는데 기여함을 의미한다. 반면에 수면 오지각에서, 불면증 심각도의 관계에서 우울을 제외한 총효과는 유의미 하지 않은 것으로 나타났다 $(\mathrm{B}=5.38, \mathrm{SE}=2.90, p=0.07)$. 더불 어 수면 오지각이 불면증으로 향하는 직접효과가 통계적으 로 유의미하지 않은 것으로 나타났다 $(\mathrm{B}=-0.89, \mathrm{SE}=2.62$, $p=0.76)$. 이를 통해 수면 오지각이 불면증의 심각도의 관계 에서 우울의 완전매개 효과를 검증하였으며 이는 수면 오지 각이 우울과 동반되었을 때, 불면증의 심각도에 정적으로 기 여할 수 있음을 의미한다.

\section{고 찰}

\section{연구 결과에 대한 논의}

본 연구는 불면증을 호소하는 성인 남녀를 대상으로 수면 오지각과 우울, 불면증 심각도 간에 어떤 연관성이 있는지 알아보고, 수면 오지각이 불면증에 미치는 영향에서 우울의 매개효과를 검증하여 이를 통해 수면 오지각이 불면증을 악 화시키는 기제를 탐색하고자 하였다. 본 연구의 주요 결과와 시사점은 다음과 같다.
첫째, 본 연구는 불면증 환자를 대상으로 주관적인 수면 지 표인 수면일지와 객관적인 수면 측정도구인 액티그래피를 활용하여 수면 오지각을 확인하였다. 현재 불면증의 진단은 주로 환자의 주관적 호소에 의존하여 이루어지고 있다. ${ }^{6}$ 본 연구를 통해 불면증 환자들이 주관적으로 경험하는 수면과 실제 수면에 차이가 있으며, 주관적인 보고만으로는 정확하게 불면증 환자의 수면을 반영하지 못할 가능성을 확인하였다.

더불어 불면증을 진단하는데 있어 주관적인 측정도구를 보완할 수 있는 객관적인 수면 측정도구의 필요성을 재고하 였으며, 수면다원검사의 한계를 보완할 수 있는 액티그래피 를 활용하였다는 점에서 의미가 있다. 수면의 객관적인 측정 도구로서 가장 널리 활용되는 도구는 수면다원검사이다. ${ }^{31}$ 그러나 수면다원검사의 경우 비싼 비용과, 통제된 환경에서 수면을 측정한다는 점에서 실제 임상장면에서 활용되기에는 한계가 있다. ${ }^{32}$ 액티그래피는 수면다원검사에 비해 비용이 저렴하기 때문에 경제적이며, 내담자가 착용하여 생활한다 는 점에서 실제 수면을 반영할 수 있기 때문에 생태학적 타 당도도 높다. ${ }^{33}$ 본 연구에서는 수면다원검사를 보완할 수 있 는 객관적인 수면 측정도구로서 액티그래피를 제안했다는 점에서 의의가 있다.

둘째, 수면 오지각과 우울, 우울과 불면증 심각도 간의 유 의한 정적인 상관이 있음을 확인하였다. 이와 같은 결과는 수면 오지각이 심각할수록 우울 또한 심각해지는 정적인 상 관을 보인 선행연구와 일치한다. ${ }^{34}$ 더불어, 선행연구에서 제 안되었던 수면 오지각과 우울, 불면증 심각도 간의 정적인 연관성과 일치하는 결과이다. ${ }^{16}$

반면, 선행 연구에서 제시되었던 수면 오지각과 불면증 심 각도 간의 유의미한 상관이 본 연구에서는 나타나지 않았다. 이는 본 연구에서 표집한 만성 불면증 환자 집단의 특징이 반영된 결과일 수 있다. 본 연구는 DSM-5에서 명시된 불면 증 기준을 만족하는 환자를 모집하였으며, 그 중 다수는 증 상이 6 개월 이상 지속된 만성 불면증 환자에 해당하였다. 본 연구에 참여한 불면증 환자 77 명의 평균 불면증 심각도는 중 등도 이상의 심각도를 보이고 있다(평균 $18.15 \pm 4.25)$. 이는 본 연구에서 중등도 이상의 심각한 불면증 환자로 표집을 제 
한했기 때문에 나타난 결과라고 추측할 수 있다. 이러한 표 집은 집단의 변산성을 제한적으로 반영하여 선행 연구에서 시사한 수면 오지각과 불면증 심각도 간의 정적 상관관계를 나타나지 못하였을 가능성이 있다. 더불어, 본 연구는 불면증 환자들의 수면 오지각과 수면 지표, 불면증 심각도를 모두 동 시간대에 측정하였다. 이와 같이 횡단 자료를 활용하였기 때문에 수면 오지각이 불면증 심각도에 영향을 미치는 데 필요한 시간의 효과를 포함하지 못하였을 가능성이 있다. ${ }^{35}$

셋째, 본 연구는 수면 오지각과 불면증 심각도와의 관계에 있어 우울의 완전 매개효과를 확인하였다. 이를 통해 수면 오지각을 보이는 불면증 환자들이 심각한 불면증으로 발전 하는 데 우울이 매개할 수 있다는 가능성을 최초로 검증하였 다는 데 의의가 있다. 최근 수면 오지각이 불면증에 미치는 기제에 대한 연구의 필요성이 제기되었으나 여전히 적은 수 의 연구가 이루어져왔다. $79,36,37$ 대부분의 선행 연구에서는 수 면 오지각이 심각해질수록 우울이 증가하는 수면 오지각과 우울의 연관성을 탐색해왔다. ${ }^{10,12-14}$ 기존 연구에서는 수면 오 지각에 대한 개입이 수면 오지각을 감소시킴과 동시에 심리 적 고통감을 감소시키며, 더 나아가 우울과 불면증 심각도를 유의하게 개선시킬 수 있음을 확인하였다. 36,38 그러나 본 연구 결과는 더 나아가 우울이 수면 오지각이 심각한 불면증으로 발전하는 데 위험요인으로 작용할 수 있는 가능성을 통계적 으로 검증하였다는 데 의미가 있다.

넷째, 본 연구 결과는 임상 장면에서 수면 오지각이 있는 불면증 환자의 불면증을 완화하기 위한 효과적인 치료적 방 향을 제시하였다. 본 연구는 수면 오지각과 불면증과의 관계 에 있어 우울의 매개 효과를 검증함으로써 수면 오지각을 보 이는 불면증 환자들에 대하여 우울에 대해 적절히 개입하는 것이 불면증 완화에 도움이 될 수 있음을 시사한다. 더 나아 가 추후 연구에서 수면 오지각 치료에 대한 근거가 될 수 있 는 방향성을 제시하였다는 데 임상적 의의가 있다.

현재까지 수면 오지각 치료는 그 필요성에 비해 제한적으 로 연구되어 왔다. 수면 오지각에 대한 치료 연구를 살펴보 면, Bayley는 다양한 외래 환자 중 주관적인 불면 증상을 호 소하는 환자들을 대상으로 1회의 수면 오지각에 대한 피드 백이 수면 오지각과 정서에 미치는 영향을 알아보았다. ${ }^{36}$ 더 불어 Tang과 Harvey는 불면증 환자를 대상으로 무선적으로 두 집단을 나누어 수면 오지각에 대한 피드백을 진행했다. ${ }^{38}$ 선행연구 결과, 수면 오지각에 대한 개입은 수면 오지각을 감소시키며 불면증과 더불어 수면과 관련한 불안, 심리적 고 통감 역시 완화하는 것을 확인하였다. ${ }^{36,38}$ 그러나 선행 연구 들은 모두 명확한 한계가 있다. 현재까지의 치료연구는 수면 오지각의 피드백에 대한 효과만을 제한적으로 검증하여, 수
면 오지각과 불면증의 관계 기제에 대한 충분한 고려가 부 족하였다. 또한, 피드백에 대한 반응을 비교하는 대조군을 포함하지 않았기 때문에 개입을 통해 나타난 불면증과 우울 및 불안의 감소가 시간의 경과에 따른 효과일 수 있는 가능 성이 있으며, 단기간의 추적 연구이기 때문에 수면 오지각 개입에 대한 치료적 효과를 평가하기 위해서는 장기적인 영 향을 관찰할 수 있는 종단 연구가 필요하다. 수면 오지각은 불면증 환자의 약 절반 이상에서 관찰되는 만연한 증상이며, 불면증을 악화시킬 수 있는 중요한 요인들 중 하나로 대두 되고 있기 때문에, 수면 오지각의 치료에 대한 연구가 현재 보다 더 적극적으로 이루어져야 할 필요가 있다.

\section{제한점 및 후속 연구를 위한 제언}

본 연구의 제한점과 후속 연구를 위한 제언은 다음과 같다.

첫째, 본 연구는 불면증 환자에게서만 나타나는 수면 오지 각을 연구하기 위해 DSM-5에서 명시하는 불면증 진단기준 을 만족하는 만 18 세에서 40 세 사이의 불면증 환자를 모집 하였다. 그러나 수면 무호흡과 일주기리듬 수면-각성 장애 와 같은 기타 수면-각성 장애를 보이는 집단이 불면증 표본 집단에 포함되었을 가능성이 있으므로, 추후 연구에서 기타 수면-각성 장애를 스크리닝 할 필요성이 제기된다.

둘째, 본 연구 대상자들의 불면증 심각도는 평균 중등도 이상으로 대다수가 심각한 수준의 불면 증상을 보이고 있는 것으로 나타났다. 이는 불면증 집단의 변산성을 제한적으로 반영하였을 가능성이 있다. 수면 오지각과 불면증 심각도와 의 관계를 살펴보기 위해서는 보다 경미한 수준의 불면증 환 자부터 심각한 수준의 불면증 환자까지 다양한 수준의 심각 도를 보이는 불면증 환자를 표집할 필요가 있다. 추후 연구 에서는 연구 대상기준을 완화하여 다양한 심각도의 불면증 환자를 표집할 것을 제안한다.

셋째, 본 연구는 수면 오지각과 불면증 심각도의 관계에서 우울의 매개효과를 분석하기 위해 횡단 자료를 활용하였다. 그러나 MacKinnon은 변수들 간의 관계에서 제 3 변수의 효 과를 검증하기 위해서는 종단자료를 사용할 필요가 있다고 주장하였다. ${ }^{39}$ 본 연구의 특성상 측정 변인들 간의 인과관계 를 밝히는 데 한계가 있기 때문에 추후 연구에서 종단자료를 사용하여 매개효과를 재검증할 필요가 있다.

이러한 제한점에도 불구하고, 본 연구는 다음과 같은 의의 를 가진다.

본 연구는 불면증 환자를 대상으로 수면 오지각과 우울, 불면증 심각도 간의 연관성을 확인하였으며, 임상적 수준의 우울이 있는 불면증 환자에게서 주관적인 수면 지표와 객관 적인 수면 지표의 유의미한 차이를 확인하여, 우울 수준에 
따른 수면 오지각과 불면증 심각도에서 차이가 있음을 확인 하였다. 이와 더불어 수면 오지각과 불면증 심각도와의 관계 에 있어 우울의 매개효과를 검증하였다. 이를 통해, 수면 오 지각이 불면증의 유지 및 심화하여 만성화 되는 기제에 대 한 이해를 증진하였으며, 수면 오지각이 불면증 심각도에 기 여하는 기제를 최초로 검증하였다는 점에서 의의가 있다. 마 지막으로, 본 연구가 수면 오지각이 있는 불면증 환자들이 더 심각한 수준의 불면증으로 발전하지 않도록 하기 위해, 우울에 대한 적절한 개입을 하는 데 있어 치료적 근거로서 활용될 수 있을 것으로 기대한다.

\section{Acknowledgments}

This work was supported by the National Research Foundation of Korea (NRF) grant funded by the Korea government (MSIT) (NRF-2017R1C1B 1008002).

\section{Conflicts of Interest}

The authors have no potential conflicts of interest to disclose.

\section{ORCID iDs}

Jiyun Lee

Eun Yeon Joo

Su Jung Choi

Sooyeon Suh https://orcid.org/0000-0002-5225-6636

https://orcid.org/0000-0003-1233-959X

https://orcid.org/0000-0003-2171-7441

https://orcid.org/0000-0003-0644-8634

\section{Author Contributions}

Conceptualization: Jiyun Lee, Sooyeon Suh. Data curation: Jiyun Lee, Sooyeon Suh. Formal analysis: Jiyun Lee. Methodology: all authors. Writing-original draft: Jiyun Lee. Writing-reveiw \& editing: Eun Yeon Joo, Su Jung Choi, Sooyeon Suh. Writing_-review \& editing: Eun Yeon Joo, Su Jung Choi, Sooyeon Suh.

\section{REFERENCES}

1. Rezaie L, Fobian AD, McCall WV, Khazaie H. Paradoxical insomnia and subjective-objective sleep discrepancy: a review. Sleep Med Rev 2018;40:196-202. https://doi.org/10.1016/j.smrv.2018.01.002.

2. Salin-Pascual RJ, Roehrs TA, Merlotti LA, Zorick F, Roth T. Long-term study of the sleep of insomnia patients with sleep state misperception and other insomnia patients. Am J Psychiatry 1992;149:904-908. https://doi.org/10.1176/ajp.149.7.904.

3. Carskadon MA, Dement WC, Mitler MM, Guilleminault C, Zarcone VP, Spiegel R. Self-reports versus sleep laboratory findings in 122 drug-free subjects with complaints of chronic insomnia. Am J Psychiatry 1976;133:1382-1388. https://doi.org/10.1176/ajp.133.12.1382.

4. Edinger JD, Fins AI. The distribution and clinical significance of sleep time misperceptions among insomniacs. Sleep 1995;18:232-239. https:// doi.org/10.1093/sleep/18.4.232.

5. Manconi M, Ferri R, Sagrada C, et al. Measuring the error in sleep estimation in normal subjects and in patients with insomnia. J Sleep Res 2010;19:478-486. https://doi.org/10.1111/j.1365-2869.2009.00801.x.

6. Means MK, Edinger JD, Glenn DM, Fins AI. Accuracy of sleep perceptions among insomnia sufferers and normal sleepers. Sleep Med 2003;4:285-296. https://doi.org/10.1016/s1389-9457(03)00057-1.

7. Vgontzas AN, Fernandez-Mendoza J, Liao D, Bixler EO. Insomnia with objective short sleep duration: the most biologically severe phenotype of the disorder. Sleep Med Rev 2013;17:241-254. https://doi. org/10.1016/j.smrv.2012.09.005.
8. Harvey AG. A cognitive model of insomnia. Behav Res Ther 2002;40: 869-893. https://doi.org/10.1016/s0005-7967(01)00061-4.

9. Harvey AG, Tang NK. (Mis)perception of sleep in insomnia: a puzzle and a resolution. Psychol Bull 2012;138:77-101. https://doi.org/10.1037/ a0025730.

10. Fernandez-Mendoza J, Calhoun SL, Bixler EO, et al. Sleep misperception and chronic insomnia in the general population: role of objective sleep duration and psychological profiles. Psychosom Med 2011;73:8897. https://doi.org/10.1097/PSY.0b013e3181fe365a.

11. Bliwise DL, Friedman L, Yesavage JA. Depression as a confounding variable in the estimation of habitual sleep time. J Clin Psychol 1993; 49:471-477. https://doi.org/10.1002/1097-4679(199307)49:4<471::aidjclp2270490403 >3.0.co;2-7.

12. Armitage R, Trivedi M, Hoffmann R, Rush AJ. Relationship between objective and subjective sleep measures in depressed patients and healthy controls. Depress Anxiety 1997;5:97-102. https://doi.org/10.1002/ (sici) 1520-6394(1997)5:2<97::aid-da6>3.0.co;2-2.

13. Tsuchiyama K, Nagayama H, Kudo K, Kojima K, Yamada K. Discrepancy between subjective and objective sleep in patients with depression. Psychiatry Clin Neurosci 2003;57:259-264. https://doi.org/10.1046/ j.1440-1819.2003.01114.x.

14. Weiss BL, McPartland RJ, Kupfer DJ. Once more: the inaccuracy of non-EEG estimations of sleep. Am J Psychiatry 1973;130:1282-1285. https://doi.org/10.1176/ajp.130.11.1282.

15. Riemann D, Voderholzer U. Primary insomnia: a risk factor to develop depression? J Affect Disord 2003;76:255-259. https://doi.org/10.1016/ s0165-0327(02)00072-1.

16. Baglioni C, Battagliese G, Feige B, et al. Insomnia as a predictor of depression: a meta-analytic evaluation of longitudinal epidemiological studies. J Affect Disord 2011;135:10-19. https://doi.org/10.1016/j.jad. 2011.01.011.

17. Sivertsen B, Salo P, Mykletun A, et al. The bidirectional association between depression and insomnia: the HUNT study. Psychosom Med 2012;74:758-765. https://doi.org/10.1097/PSY.0b013e3182648619.

18. Staner L. Comorbidity of insomnia and depression. Sleep Med Rev 2010;14:35-46. https://doi.org/10.1016/j.smrv.2009.09.003.

19. American Psychiatric Association. Diagnostic and Statistical Manual of Mental Disorders (DSM- ${ }^{\circledR}$ ). Washington, DC: American Psychiatric Pub, 2013.

20. McCall C, McCall WV. Comparison of actigraphy with polysomnography and sleep logs in depressed insomniacs. J Sleep Res 2012;21:122127. https://doi.org/10.1111/j.1365-2869.2011.00917.x.

21. Te Lindert BHW, van der Meijden WP, Wassing R, et al. Optimizing actigraphic estimates of polysomnographic sleep features in insomnia disorder. Sleep 2020;43:zsaa090. https://doi.org/10.1093/sleep/zsaa090.

22. Ancoli-Israel S, Martin JL, Blackwell T, et al. The SBSM guide to actigraphy monitoring: clinical and research applications. Behav Sleep Med 2015;13 Suppl 1:S4-S38. https://doi.org/10.1080/15402002.2015.1046356.

23. Lambiase MJ, Gabriel KP, Chang YF, Kuller LH, Matthews KA. Utility of actiwatch sleep monitor to assess waking movement behavior in older women. Med Sci Sports Exerc 2014;46:2301-2307. https://doi. org/10.1249/MSS.0000000000000361.

24. Matthews CE, Hagströmer M, Pober DM, Bowles HR. Best practices for using physical activity monitors in population-based research. Med Sci Sports Exerc 2012;44:S68-S76. https://doi.org/10.1249/MSS.0b013 e3182399e5b.

25. Vanable PA, Aikens JE, Tadimeti L, Caruana-Montaldo B, Mendelson WB. Sleep latency and duration estimates among sleep disorder patients: variability as a function of sleep disorder diagnosis, sleep history, and psychological characteristics. Sleep 2000;23:71-79. https://doi. org/10.1093/sleep/23.1.1d.

26. Bastien $\mathrm{CH}$, Vallières A, Morin CM. Validation of the Insomnia Severity Index as an outcome measure for insomnia research. Sleep Med 2001;2:297-307. https://doi.org/10.1016/s1389-9457(00)00065-4.

27. Cho YW, Song ML, Morin CM. Validation of a Korean version of the 
insomnia severity index. J Clin Neurol 2014;10:210-215. https://doi. org/10.3988/jen.2014.10.3.210.

28. Eaton WW, Smith C, Ybarra M, Muntaner C, Tien A. Center for epidemiologic studies depression scale: review and revision (CESD and CESD-R). In: Maruish ME. The use of psychological testing for treatment planning and outcomes assessment. 3rd ed. Mahwah: Lawrence Erlbaum, 2004;363-377.

29. Lee S, Lee H, Oh ST, et al. PS223. Validation of the Korean version of Center for Epidemiologic Studies Depression scale-Revised. International Journal of Neuropsychopharmacology 2016;19(Suppl 1):81-82. https://doi.org/10.1093/ijnp/pyw043.223.

30. Baron RM, Kenny DA. The moderator-mediator variable distinction in social psychological research: conceptual, strategic, and statistical considerations. J Pers Soc Psychol 1986;51:1173-1182. https://doi.org/ 10.1037//0022-3514.51.6.1173.

31. Edinger JD, Krystal AD. Subtyping primary insomnia: is sleep state misperception a distinct clinical entity? Sleep Med Rev 2003;7:203-214. https://doi.org/10.1053/smrv.2002.0253.

32. Vgontzas AN, Kales A, Bixler EO, Manfredi RL, Vela-Bueno A. Usefulness of polysomnographic studies in the differential diagnosis of insomnia. Int J Neurosci 1995;82:47-60. https://doi.org/10.3109/ 00207459508994289.
33. Marino M, Li Y, Rueschman MN, et al. Measuring sleep: accuracy, sensitivity, and specificity of wrist actigraphy compared to polysomnography. Sleep 2013;36:1747-1755. https://doi.org/10.5665/sleep.3142.

34. Williams JM, Kay DB, Rowe M, McCrae CS. Sleep discrepancy, sleep complaint, and poor sleep among older adults. J Gerontol B Psychol Sci Soc Sci 2013;68:712-720. https://doi.org/10.1093/geronb/gbt030.

35. Cho YI, Kim J, Han WR, Jo YJ. Differences and combinations of moderational and mediational effects: definitions and statistical testing. Kor J Clin Psychol 2015;34:1113-1131. https://doi.org/10.15842/KJCP.2015. 34.4.012.

36. Bayley K. Subjective-objective discrepancies among patients with sleep complaints in the patient-centered medical home. Electronic Theses and Dissertations 2018.

37. Kay DB, Buysse DJ, Germain A, Hall M, Monk TH. Subjective-objective sleep discrepancy among older adults: associations with insomnia diagnosis and insomnia treatment. J Sleep Res 2015;24:32-39. https:// doi.org/10.1111/jsr.12220.

38. Tang NK, Harvey AG. Altering misperception of sleep in insomnia: behavioral experiment versus verbal feedback. J Consult Clin Psychol 2006;74:767-776. https://doi.org/10.1037/0022-006X.74.4.767.

39. MacKinnon DP. Introduction to statistical mediation analysis. New York: Lawrence Erlbaum Associates, 2008. 